Research Article

\title{
Comparison of HCHCr Steel and Carbide Punch and Die Increase its Strength and Life by Tin \& Ceramics coating
}

\author{
K. Nagendran ${ }^{\dot{A}^{*}}$, S. Sathish ${ }^{\dot{A}}$ and J. David Rathnaraj ${ }^{\dot{\mathrm{A}}}$ \\ ${ }^{\dot{A}}$ Manufacturing Engineering Department, Sri Ramakrishna Engineering College, Coimbatore \\ Accepted 10 January 2014, Available online 01 February 2014, Special Issue-2, (February 2014)
}

\begin{abstract}
The tools used in the Blanking process are subjected to heavy forces, such that attends to break the profile of the tool, if it is not designed properly. The main aim of this project is to analyze and redesign a tool which is subjected to frequent breakage, due to the heavy impact force, a necessary condition for the Blanking operation. Tungsten carbide is a material used for a number of industrial applications and it is characterized by its high strength, toughness, hardness and it is having carbide grain size (0.2 - 50 microns, binder contents (up to 30\%), as well as by the addition of other carbides. By varying the grain size of the tungsten carbide and the binder content in the matrix, engineers have access to a class of materials whose properties can be tailored to a variety of engineering applications. In the field of industrial engineering the factors reduction of cost, improved mechanical properties such as wear, corrosion, very high or very low temperature resistant with good harden ability and mach inability characteristics are involves important role. An attempt on optimize design and analysis of blanking punch tool to increase its strength and life by applying ceramic coating over the tool material. The analysis of tool parameters like load, stress and life of the tool are the main causes of tool wear and their model generations are created through ANSYS software. Analyses and comparison of HCHCr \& Tungsten carbide material tool which can be redesigned without affecting the final blanked profile for its strength and durability and to withstand the said extreme conditions. In this process the redesign of the tool is done initially in ProE and the final model is analyzed in ANSYS.
\end{abstract}

Keywords: ANSYS, blanking tool, Pro/E model, ceramic coatings, life calculation

\section{Introduction}

Fine blanking presses are similar to other metal stamping presses, but they have a few critical additional parts. A typical compound fine blanking press includes a hardened die punch (male), the hardened blanking die (female), and a guide plate of similar shape/size to the blanking die. The guide plate is the first applied to the material, impingingthe material with a sharp protrusion or stinger around the perimeter of the die opening. Next a counter pressure is applied opposite the punch, and finally the die punch forces the material through the die opening. Since the guide plate holds the material so tightly, and since the counter pressure is applied, the material is cut in a manner more like extrusion than typical punching. Tungsten carbide is a material used for a number of industrial applications and it ischaracterized by its high strength, toughness and hardness. Tungsten carbide as a material can vary in carbide grain size $(0.2-50$ microns $)$ and by binder contents (up to $30 \%$ ), as well as by the addition of other carbides. By varying the grain size of the tungsten carbide and the binder content in the matrix, engineers have access to a class of materials whose properties can be tailored to a variety of engineering applications.

*Corresponding author: K. Nagendran

DOI: http://dx.doi.org/10.14741/ijcet/spl.2.2014.51
Mechanical properties of the cut benefit similarly with a hardened layer at the cut edge from the cold working of the part. Because the material is so tightly held and controlled in this setup, part flatness remains very true, distortion is nearly eliminated, and edge burr is minimal. Clearances between the die and punch are generally around $1 \%$ of the cut material thickness, which typically varies between $0.5-13 \mathrm{~mm}(0.020-0.51 \mathrm{in})$.

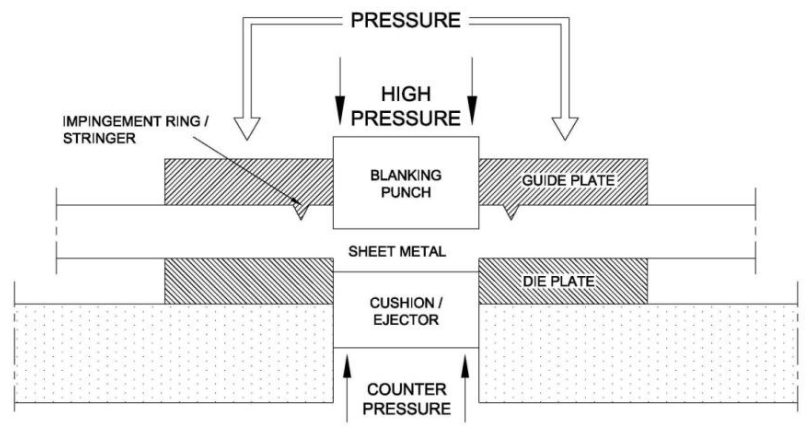

Fig 1Typical fine blanking press cross section

Currently parts as thick as $19 \mathrm{~mm}(0.75$ in) can be cut using fine blanking. Tolerances between $\pm 0.0003-0.002$ in $(0.0076-0.051 \mathrm{~mm})$ are possible based on material thickness \& tensile. Fine blanking is a specialized form of 
blanking where there is no fracture zone when shearing. This is achieved by compressing the whole part and then an upper and lower punch extracts the blank. This allows the process to hold very tight tolerances, and perhaps eliminate secondary operations.

\subsection{Materials Used For the Punch}

High-Speed Tool Steels: High-speed alloys include all molybdenum (M1 to M52) and tungsten (T1 to T15) class alloys. High-speed tools steels can be hardened to 62-67 HRC and can maintain this hardness in service temperatures as high as $540{ }^{\circ} \mathrm{C}\left(1004^{\circ} \mathrm{F}\right)$, making them very useful in high-speed machinery. Typical applications are end mills, drills, lathe tools, planar tools, punches, reamers, routers, taps, saws, broaches, chasers, and hobs.

Hot-work Tool Steels: Hot-work tool steels include all chromium, tungsten, and molybdenum class $\mathrm{H}$ alloys. They are typically used for forging, die casting, heading, piercing, trim, extrusion, and hot-shear and punching blades.

Cold-work Tool Steels: Cold-work tool steels include all high-chromium class D, medium alloy

Air-hardening class A alloys, water hardening W alloys, and oil hardening $\mathrm{O}$ alloys. Typical applications include cold working operations such as stamping dies, draw dies, burnishing tools, coining tools, and shear blades.

Shock-Resistant Tool Steels: Cold-work tool steels include all class $\mathrm{S}$ alloys. They are among the toughest of the tool steels, and are typically used for screw driver blades, shear blades, chisels, knockout pins, punches, and riveting tools

Mold Steels: Mold steels include all low-carbon and one medium-carbon class P tool steels. They are typically used for compression and injection molds for plastics.

Special-Purpose Tool Steels: Special-Purpose Tool Steels include all low-alloy class L Tool steels. They are usually quenched, which makes them relatively tough and easily machinable. They are typically used for arbors, punches, taps, wrenches, drills, and brake-forming dies.

Water-Hardening Tool Steels: Water-Hardening Tool steels include all class W tool steels, and while they do not retain hardness well at elevated temperatures, they do have high resistance to surface wear. Typical applications include blanking dies, files, drills, taps, countersinks, reamers, jewelry dies, and cold-striking dies.

\subsection{Tungsten carbide}

Tungsten carbide (WC) is an inorganic chemical compound (specifically, a carbide) containing equal parts of tungsten and carbon atoms. In its most basic form, tungsten carbide is a fine gray powder, but it can be pressed and formed into shapes for use in industrial machinery, cutting tools, abrasives, other tools and instruments, and jewelry.
Tungsten carbide is approximately three times stiffer than steel, with a Young's modulus of approximately $550 \mathrm{GPa}$ and is much denser than steel or titanium. It is comparable with corundum ( $\alpha-\mathrm{Al} 2 \mathrm{O} 3)$ or sapphire in hardness and can only be polished and finished with abrasives of superior hardness such as cubic boron nitride and diamond, in the form of powder, wheels, and compounds.

\subsection{Chemical properties}

There are two well characterized compounds of tungsten and carbon, WC and tungsten semi carbide, W2C. Both compounds may be present in coatings and the proportions can depend on the coating method. At high temperatures WC decomposes to tungsten and carbon and this can occur during high-temperature thermal spray, e.g., in high velocity oxygen fuel (HVOF) and high energy plasma (HEP) methods. Oxidation of WC starts at 500-600 ${ }^{\circ} \mathrm{C}$. It is resistant to acids and is only attacked by hydrofluoric acid/nitric acid (HF/HNO3) mixtures above room temperature. It reacts with fluorine gas at room temperature and chlorine above $400{ }^{\circ} \mathrm{C}\left(752^{\circ} \mathrm{F}\right)$ and is un reactive to dry $\mathrm{H} 2$ up to its melting point. $\mathrm{WC}$ dissolves readily in diluted hydrogen peroxide.

\subsection{Physical properties}

Tungsten carbide has a high melting point at $2,870{ }^{\circ} \mathrm{C}$ $\left(5,200{ }^{\circ} \mathrm{F}\right)$, a boiling point of $6,000{ }^{\circ} \mathrm{C}\left(10,830{ }^{\circ} \mathrm{F}\right)$ when under a pressure equivalent to $760 \mathrm{~mm}$ of $\mathrm{Hg}$, a thermal conductivity of $84.02 \mathrm{~W} \cdot \mathrm{m}-1 \cdot \mathrm{K}-1$, and a coefficient of thermal expansion of $5.8 \mu \mathrm{m} \cdot \mathrm{m}-1 \cdot \mathrm{K}-1$. Tungsten carbide is extremely hard, ranking $\sim 9$ on Mohs scale, and with a Vickers number of 1700-2400. It has a Young's modulus of approximately $550 \mathrm{GPa}$, a bulk modulus of $439 \mathrm{GPa}$, and a shear modulus of $270 \mathrm{GPa}$. It has a ultimate tensile strength of $344.8 \mathrm{MPa}$.The speed of a longitudinal wave (the speed of sound) through a thin rod of tungsten carbide is $6220 \mathrm{~m} / \mathrm{s}$. With a low electrical resistivity of $\left(\sim 2 \times 10^{-7}\right.$ Ohm $)$, tungsten carbide's resistivity is comparable with that of some metals (e.g. vanadium $2 \times 10$ $-7 \mathrm{Ohm})$.

WC is readily wetted by both molten nickel and cobalt.[17] Investigation of the phase diagram of the W-CCo system shows that WC and Co form a pseudo binary eutectic. The phase diagram also shows that there are socalled $\eta$-carbides with composition (W,Co)6C that can be formed and the fact that these phases are brittle is the reason why control of the carbon content in WC-Co hard metals is important.

\subsection{Applications}

Sintered tungsten carbide cutting tools are very abrasion resistant and can also withstand higher temperatures than standard high speed steel tools. Carbide cutting surfaces are often used for machining through materials such as 
carbon steel or stainless steel, as well as in situations where other tools would wear away, such as high-quantity.

Production runs. Because carbide tools maintain a sharp cutting edge better than other tools, they generally produce a better finish on parts, and their temperature resistance allows faster machining. The material is usually called cemented carbide, hard metal or tungsten-carbide cobalt: it is a metal matrix composite where tungsten carbide particles are the aggregate and metallic cobalt serves as the matrix. Manufacturers use tungsten carbide as the main material in some high-speed drill bits, as it can resist high temperatures and is extremely hard.

\subsection{Mechanical properties}

Strength - Tungsten carbide has very high strength for a material so hard and rigid. Compressive strength is higher than virtually all melted and cast or forged metals and alloys. Rigidity - Tungsten carbide compositions range from two to three times as rigid as steel and four to six times as rigid as cast iron and brass. Young's Modulus is up to $94,800,000$ psi. High resistance to deformation and deflection is very valuable in those many applications where a combination of minimum deflection and good ultimate strength merits first consideration. These include spindles for precision grinding and roll for strip or sheet metal. Impact Resistant - For such a hard material with very high rigidity, the impact resistance is high. It is in the range of hardened tool steels of lower hardness and compressive strength.

Heat and oxidation resistance - Tungsten-base carbides perform well up to about $1000^{\circ} \mathrm{F}$ in oxidizing atmospheres and to $1500^{\circ} \mathrm{F}$ in non-oxidizing atmospheres Low temperature resistance (cryogenic properties) - Tungsten carbide retains toughness and impact strength in the cryogenic temperature ranges. $\left(-453^{\circ} \mathrm{F}\right.$.) Thermal Conductivity - Tungsten carbide is in the range of twice that of tool steel and carbon steel.

\subsection{Titanium nitride coating for superior tool performance}

In these days if intense industrial competition, the cost savings and productivity improvements associated with titanium nitride coating of cutting tools are too important to ignore. If tool engineers want to act aggressively, they would use this coating in every situation possible. A Titanium nitride (TiN) coating has a hardness of about 80 Rc and a coefficient of friction about one-third that of the steel substrate. The coating protects tools from abrasive wear, and the lubricate reduces friction, heat, and the buildup which forms on tool edges during use. TiN coated tools generally pay for themselves the first time they are used. The coating reduces cutting forces by about $17 \%$ in most drilling application, and carbon-steels. When punching galvanized steel, carbon steels. Bronze, and soft iron, longer tool life is reported when the punches are coated. The punches have less material build-up on their sides and less galling.

Stripping action is also improved. In Semi warm operations. Excellent results can be expected. But coating forging dies is not recommended. Punches and forming tools made of D2 tool steel should be hear treated with 3Tempers of 950 - F; this ensures dimensional stability and no loss of hardness when the tool is subjected to the coating process temperature. Applying TiN to moulds is very beneficial. Material build-up, like rubber or plastic, is easier to remove. The best tool surface for coating is finely ground, clean, and with no prior treatment. That means no nitride, black oxide, or any other surface treatment

\subsection{Process description}

In this coating process, the tools to be coated must be physically and chemically clean. They are positioned in the fixtures which are the cathode o a high voltage system in a reaction chamber. The chamber is evacuated and charged with argon for a process called Sputter cleaning. The positive argon ions are propelled by a high voltage field to blast the tools so they become atomically clean. Titanium is heated by electron beam until it evaporates. At this time, nitrogen is introduced into the chamber and the titanium ions are electrically accelerated toward the tools. The titanium ion bombardment combines with the nitrogen gas to form a coating of titanium nitride about 0.0001 thick on the exposed surfaces of the tools.

The adhesive bond between the coating and the matrix is so tight; coating does no separate due to deflection when the tools are used. The coating process described above, called 'Physical Vapor Deposition' (PVD), operates at about $900 \cdot$, which is well below the tempering temperature of high speed steel. That means hardened tools will not soften during the coating process. There is another coating process, called 'chemical Vapor Deposition' (CVD), which operated at a temperature of 1750-1950 - F. It was originally developed to coat carbide inserts; however, if tool steel is coated by this process, oil would soften and require re hardening. For thesis reason, the PVD process is normally used for coating tools. The performance of carbide tools coated by PVD is improved because the process minimizes edge embitterment. The disadvantage of CVD is that it tends to round over sharp edges and thicken corners.

\subsection{Break-In Period}

When cutting tools are first used, they develop a wear land during the break-in period. The wear of the cutting edge then proceeds at a much slower pace; this is called the low wear period. The useful life of the tool continues until rapid edge breakdown begins to occur. At this time, the tool should be sharpened. When a tool is titanium nitride coated, the low wear period is extended far beyond that of uncoated tools. Forming tools, plastic moulds, and mould components coated with titanium nitride show similar reduced wear characteristics There are numerous reports detailing dramatic improvements in tool life and productivity due to the use of TiN - coated drills, end mills , milling cutters and other high speed steel tools. Tincoated tools are now used on all metal removal operations to extend tool life, increase feeds and speeds, and reduce machine downtime. Three areas should be considered by those who would like understand the advantages of coated 
tools; the tool quality, the consistency of the quality , and the tool performance.

\subsection{Ceramic coatings}

Ceramic coatings, which offer the excellent properties of ceramics such as high hardness and wear resistance, electrical insulation, low thermal conductivity and reproducible surface structures, are used for surface protection Thick film and thin film techniques are differentiated in the manufacture of ceramic coatings. Thick films $(>20 \mu \mathrm{m})$ are applied, for example, by thermal spraying. Plasma spraying has shown excellent results in this application. During plasma spraying, oxide ceramic powder or powder mixtures such as aluminium oxide, aluminium oxide / titanium dioxide, zirconium oxide and chromium oxide are melted in a plasma flame atapprox. $10,000{ }^{\circ} \mathrm{C}$ and sprayed on a previously sandblasted metal surface. However, it is necessary to ensure that before plasma spraying a fissured surface is created through sandblasting to which the ceramic particles can cling as they arrive. Several layers are applied, so that a lamellar layer structure with good adhesion results.

These coating procedures using ceramics are suitable for experimental batches of 1 to 10 as well as for production series of 10,000 or more. The procedure offers a facility for rapid production at short notice. It allows metal parts to be created on CNC machines, coated and further processed within a few days. Repair coatings are also of interest. Used ceramic coatings that have been damaged by shocks and impacts during heavy use can simply be sandblasted away. Expensive metal parts can be re-ground and coated with ceramic again. Plasma sprayed coatings have proved themselves, for example, in textile and wire drawing machines. Thin films $(<20 \mu \mathrm{m})$ are applied by PVD (physical vapour deposition) or CVD (chemical vapour deposition), by galvanic processes or by sol-gel processes. Here, for example, tools with the familiar gold colored TiN coatings have found wide acceptance.

Table 1 Comparison of mechanical properties in $\mathrm{HCHCr}$ and Tungsten carbide materials

\begin{tabular}{|l|l|l|}
\hline Description & HCHCR & Tungsten carbide \\
\hline Density & 7.7 & $15.63 \mathrm{~g} / \mathrm{cm} 3$ \\
\hline Young's modulus & --- & $411 \mathrm{GPa}$ \\
\hline Elastic modulus & $190-210$ & --- \\
\hline Poisson ratio & $0.27-0.30$ & 0.28 \\
\hline Shear modulus & & $161 \mathrm{GPa}$ \\
\hline
\end{tabular}

\section{Problem identification \& methodology failure mode}

The data's regarding the existing system prevailing in the Blanking process which produces frequent breakdown are collected and analyzed. In scrutinizing these data's and the processes a conclusion is arrived that the punch is the most subjected part to failure and causing the frequent breakdown. In the detailed study of the punch and the die and the process of the blanking, it is found that the weaker areas of breakage of the punch is indicted as shown in the figurer.

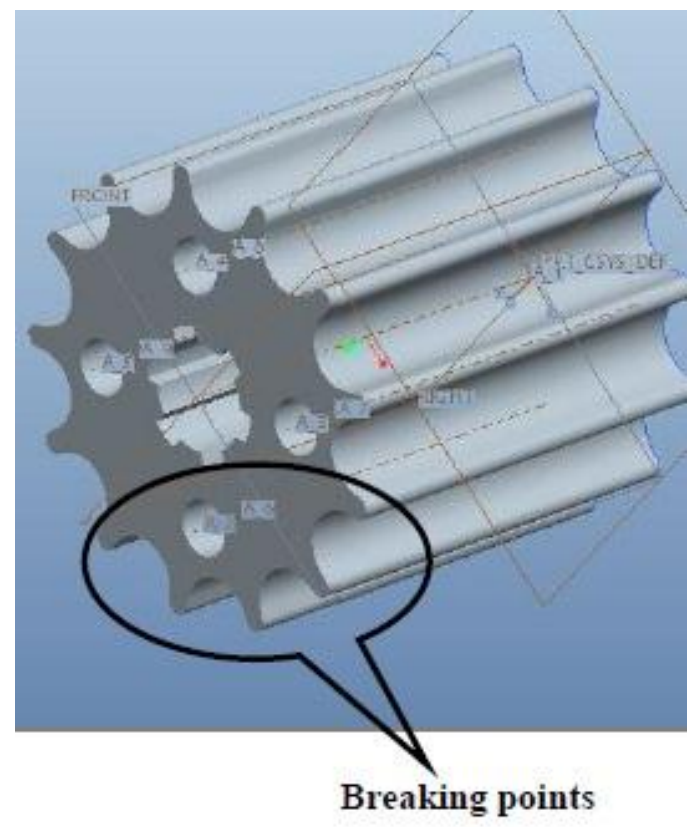

Fig 2 Blanking punch showing its failure points

\subsection{Details of the punch with its working nature}

Table 2 Details of the punch

\begin{tabular}{|l|l|}
\hline Material & HCHCr-D2 steel \\
\hline Coating & TiN \\
\hline Profile & Wire cut \\
\hline Hardness & $56-58$ HRC \\
\hline Blanking Load & 106.38 Tons \\
\hline Avg. usage & 6000strokes/3Shifts \\
\hline Nature of breakage & $\begin{array}{l}\text { As indicated in the figure the } \\
\text { tips of the tool is subjected to } \\
\text { breakage to a length of 10mm } \\
\text { approx. }\end{array}$ \\
\hline Frequency of Breakage & 10000 Strokes approx \\
\hline
\end{tabular}

\subsection{After effects of the problem}

- Production delay

- Dismantling the Worn-out punch and re-assembling with a new punch, a new Punch should be kept ready at any time during the time of breakdown

- Manufacturing a new punch-Turning, hardening, Wire cutting etc.

- The Total cost for manufacturing new punch Rs.5470 has to be spent

- The above designated problems can be solved by redesigning the punch by adding strength and wear resistance. For which change the material part in the shape of the profile in the end of the punch such that it will be a carbide material is high strength and wear resistance property. Manufacturing this punch will save material and money, by reducing the material quantity, machining, wire cutting. 


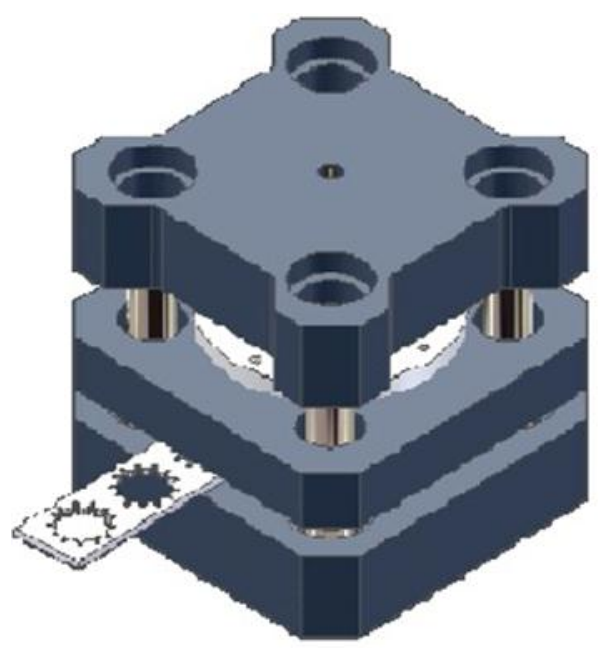

Fig. 3 Blanking Tool

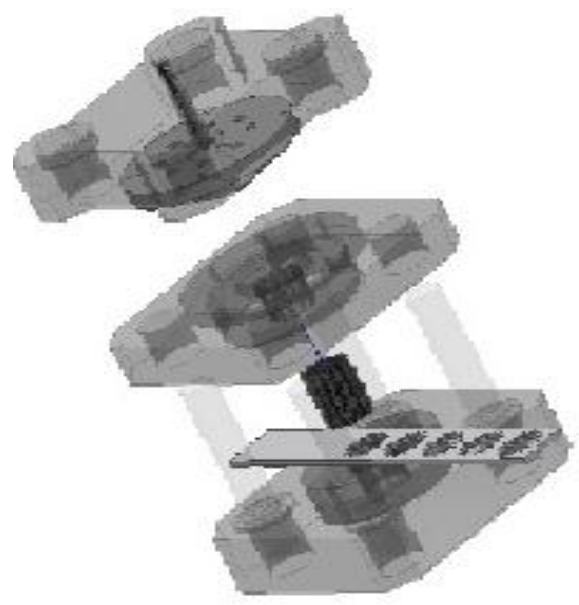

Fig 4 Exploded view of blanking tool

\section{Methodology}

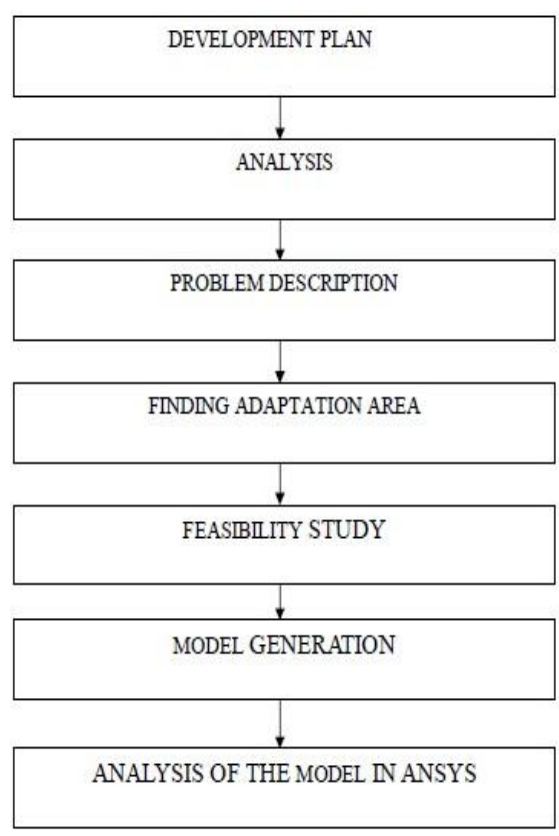

Fig 5 Methodology

\subsection{General analysis}

The problem that is faced by this blanking die is to be analyzed to rectify the problem. To obtain the optimization, the detailed analysis is needed in the field of designing the punch. To do this various drawings of the Blanking Die are collected and studied. The details about material of construction and the nature of working are studied.

\subsection{Problem description}

The Punch which is subjected to heavy loads has a frequent breakage in the profile as shown in the figurer for about $10 \mathrm{~mm}$ minimum height.

\section{Analysis of model in Ansys}

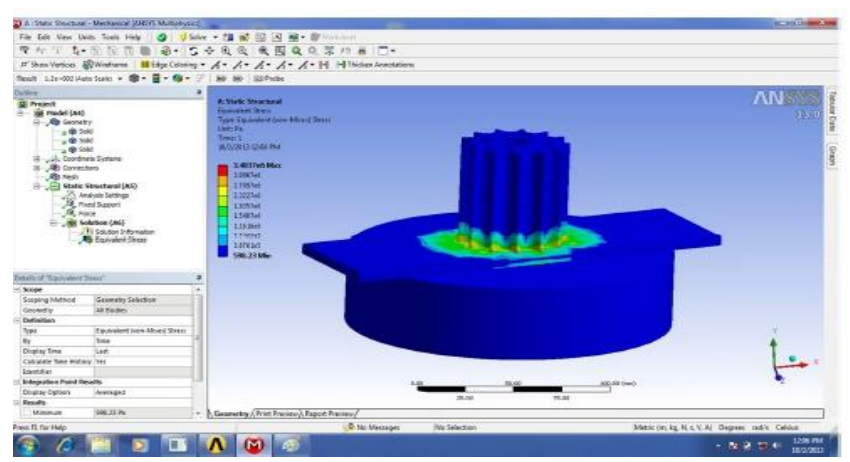

Fig 6 Model showing stress calculation of $\mathrm{HCHCr}$ material

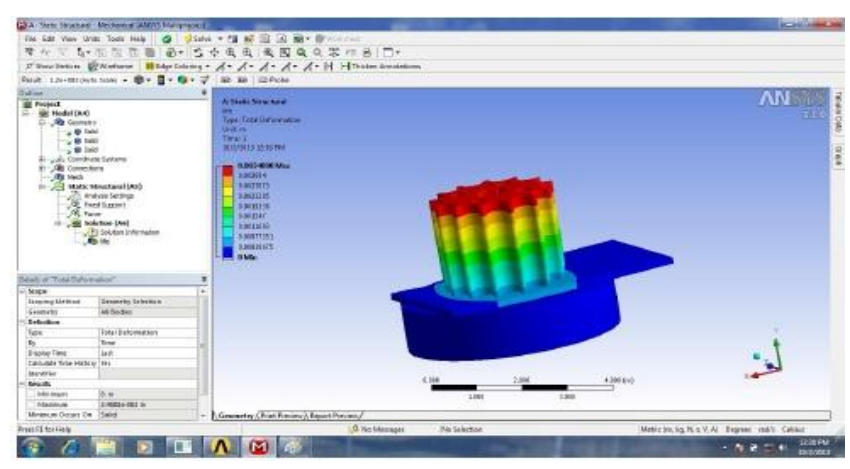

Fig 7 Model showing life calculation of $\mathrm{HCHCr}$ material

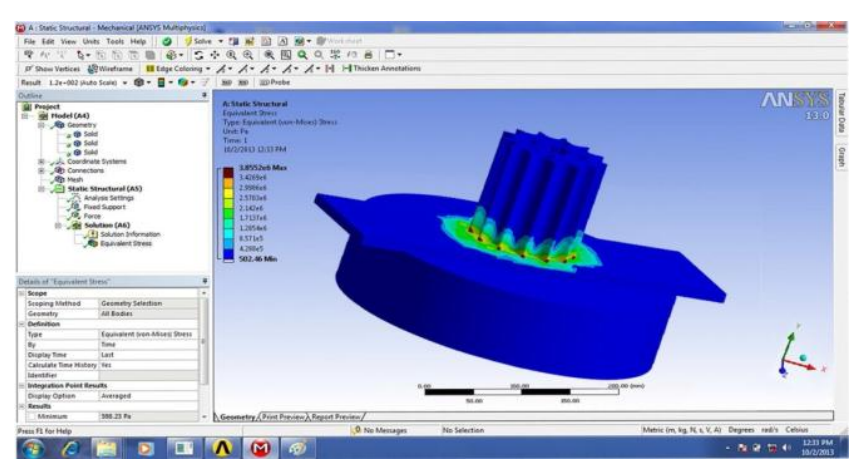

Fig 8 Model showing stress calculation of tungsten carbide material

285 | International Conference on Advances in Mechanical Sciences 2014 


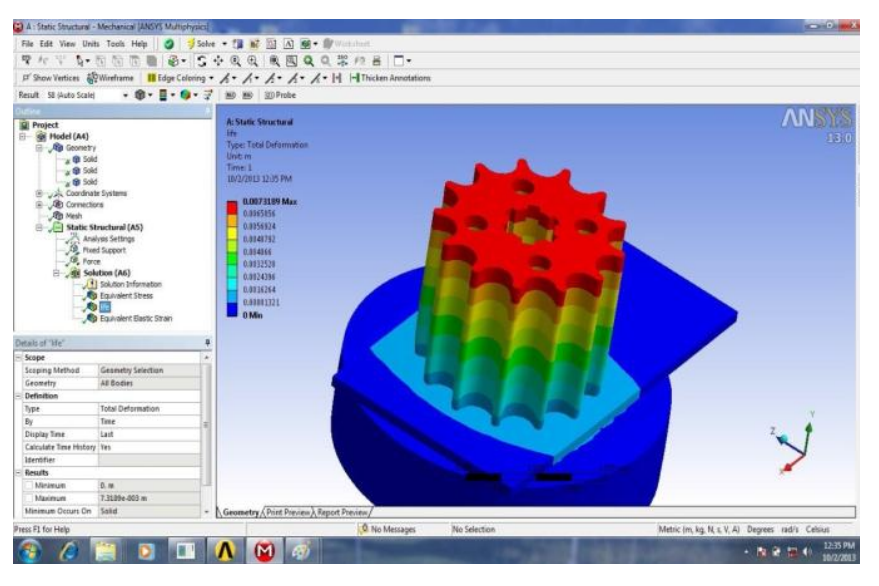

Fig 9 Model showing life calculation of tungsten carbide material

\section{Results and Discussion}

Table 3 Comparison of result

\begin{tabular}{|l|l|l|l|}
\hline $\begin{array}{l}\text { S. } \\
\text { No }\end{array}$ & Parameters & HCHCr & Tungsten carbide \\
\hline 1 & Load N & 1.6262 X10+005 & 1.6262 X10+005 \\
\hline 2 & Stress N/m2 & $\begin{array}{l}\text { Max:3.4837 } \\
\text { Min:598.23 }\end{array}$ & $\begin{array}{l}\text { Max:3.8552 } \\
\text { Min:502.46 }\end{array}$ \\
\hline 3 & $\begin{array}{l}\text { Life } \\
\text { (In terms of travel } \\
\text { length in m.) }\end{array}$ & Max:0.0034808 & Max:0.0073189 \\
\hline
\end{tabular}

By the Result from the Ansys load character for the HCHCR punch die and the Tungsten Carbide punch die are the same due the application. The results shows the Stress level in the HCHCR is comparatively low than the Tungsten Carbide die, means the Tungsten carbide can withstand more stress load for the Blanking Operation in industry. Relatively with the carbide grain size, and the binder of the Tungsten Carbide having the more life cycle than the HCHCR for the blanking application.

\section{Conclusion}

Blanking is one of the inevitable operations that cannot be avoided most often in the industries. If the life of the blanking tool can be improved somehow, then the reliability and the quality of the components will also be improved. In order to do that the rigidity must be maintained throughout its life time. Based on the study of punch and other critical components that are prone to failure using FEM, the durability is found to be improved at elevated temperature. Design in solid modeling and analysis using ANSYS allows us to draw following conclusions.

- The punch can survive extreme forces and still maintain its rigidity.

- The significant improvement in the wear resistance is the reason for this and it is achieved by applying coatings over the punch.

- After the failure analysis through FEM tungsten carbide punch with coating of ceramics $20 \mu \mathrm{m}$ comparatively better life than HCHCR punch with coating of TiN, it means that wear resistant of tungsten carbide punch is more and life cycle for the operation.

\section{References}

Banga,T.R \& Sharma, (2006) Mechanical Estimating \& Casting Khanna publishers

Groover.P Mikell \& Zimmers.W Emory Jr. (1998) CAD / CAM computer aided design \& manufacturing Prentice Hall of India (P) Ltd. Nineteenth edition.

Narang G.B.S. \& Kumar.V, (2005) Production \& Costing Khanna publishers, Fourth edition

Ridha hambli, (1999) Blanking tool wear modeling using the finite element method. The prediction of tool wear in sheet metal blanking/punching processes is investigated in this paper using the finite element method

R M Redfem, (2011) Selection of die materials and surface treatments for increasing die life in hot and warm forging FIA Tech Conference

U.P. Singh, A.H.Streppel and H.J.J.Kals, (2002) Design study of the geometry of a punching blanking tool

G. Straffelini a,, G.Bizzottob, V. Zanonb, (2005) Improving the wear resistance of tools for stamping

Boris Tomov, (1998) A mechanical device for measuring the displacement and Rotation of a blanking or forging press Journal of material Processing Technology, 70-72

Heinrich Klaasen, (2004) Wear of advanced cemented carbides for metal forming tool materials 846-853

Felix Faura, Miguel, (2001) A decision support for sheet metal blanking process parameter selection Journal of material Processing Technology, 371-376 